Adoress.

\section{SECTION ON STOMATOLOGY.} ADDRESS OF CHAIRMAN.* BY M. H. FLETCHER, M.D. CINCINNATr, OHIO.

The compliment of having been elected as your Chairman is highly appreciated, but the pleasure is largely counteracted by my inability to return something of value to you in the form of scientific research. I have partly finished a series of investigations on the formation of bone from periosteum, and cementum from the pericementum, but press of other matters did not allow time for their completion, so their results will have to be presented on another occasion.

'The symposiums on "Dental Education" and "Interstitial Gingivitis," which are to take 'up most of the time of this year's meeting, are especially important to us.

Much to the credit of our specialty, it may be said that the past five years have seen great advancement in teaching dentistry, as is shown for instance, by the proceedings of "The National School of Dental Technics" Advancement in the branches discussed at this school, apparently has stimulated greater effort in other departments of dental pedagogics.

As to the diseases of the tissues about the teeth, much can be said at the present time, but it is probable that many more facts will be in our possession at the end of another decade, for to-day finds in the ranks of our specialty, a greater number of trained scientific investigators than ever before, and many of them are giving much attention to the tissues under discussion, both histologically and pathologically, all of which will bring its fruit in due time.

Among other points which are unsettled about this subject is the nomenclature; and the present year seems especially fruitful in new names. When there is a choice of ways, the laws of natural selection usually prevail, and the survival of the fittest is the result. In order that Nature may have an abundance of material from which to select, I wish to add to the already long list of names under discussion, by nominating a term which may be old, but which seems to me to be the one of natural selection as compared with the others suggested, namely, "peridentiti:s."

"Pyorrhea alveolaris," indicating a flow of pus from the sockets of the teeth, is clearly a poor choice. "Alveolitis" or "chronic alveolitis," suggested by Dr. Henry Nash, does not seem to cover the case in a generic way much better than the former, since the socket, or bone, indicated by the word "alveolitis" is only a part of the tissues involved. The term "interstitial gingivitis," used by Talbot, is admitted by him to be deficient, and it seems especially so as to the term "gingivitis," since this name clearly indicates the gums and no other tissue, whereas all the tissues about the teeth may become involved; so we apparently need a generic name composed of one word in order to be acceptable, and this demand seems to be met in the term "peridentitis," for the following reasons: Peri is a Greek term of Latin origin, meaning around, about, or near; dent, or dens, is the Latin for tooth, and also a Greek term of Latin origin, and a termination used in modern pathologic nomenclature, to signify inflammation of the part indicated.

*Presented to the Section on Stomatology, at the Fifty-first Annual Meeting of the American Medical Association, held at Atlantic City, N. J., June 5-8, 1900
A comparable term to this is that of "periadenitis," indicating inflammation of the tissue surrounding a gland.

The adoption of "peridentitis" or some comparable term used as a generic name, admits of the use of descriptive adjectives for the varieties, specific stages, or pathologic conditions of the tissue surrounding the teeth; for example, acute peridentitis, or chronic suppurative, sloughing, necrotic peridentitis, indicating death of bone, etc.

This term is distinguished from pericementitis, which indicates an acute stage of inflammation of the peridental membrane; and from our standpoint, seems to fulfil the demands in the case, being quite comparable to terms adopted for similar descriptive use in other parts of the body.

\section{Driginal Articles.}

\section{IDENTAL AND ORAL SURGERY.}

\section{ITS RELATION TO THE GENFRAL FIELD OF MEDIGINE AND SURGERY, AND THE TRUE PROFESSIONAL STATUS OR RANK OF THE PROPERIY EDUCATED PRACTI- \\ TIONER OF DENTAL AND ORAL SURGERY.* BY N. S. DAVIS, M.D., LI.D. \\ CHICAGO.}

The American Dental Association was organized in Washington, D. C., in July, 1860, by twenty-three delegates representing the chief dental societies and dental colleges then existing in the country.

The fifth annual meeting of the Association was held in Chicago during the last week in July, 1865, and its members were welcomed in a brief but excellent address by the late W. W. Allport, D.D.S., M.D., of that city. On the evening of July $2 \%, 1865$, during the annual meeting, I had the pleasure of entertaining the members in my own home, and was called on to respond to the following sentiment offered by Dr. C. W. Spaulding, then president of the Association: "To the President of the American Medical Association, Medicine, Surgery, and Dentistry, departments of a common science, their disciples should constitute a common brotherhood." 1 I can not now, after thirty-five years have passed, give a better expression of my present views concerning the true relations of dental and oral surgery to the general field of medicine than by quoting a large part of the response made by me on that occasion, as follows: That medicine, surgery, and dentistry are actually departments of a common science, very few will be disposed to deny. I say a "common science" in deference to popular custom. It would be more proper, however, to use the plural form of expression, for what is generally styled medical science is really an aggregation of many sciences and their cultivation with direct reference to the prevention and alleviation of human suffering. The science of medicine properly so-called consists of facts and principles selected from every department of the natural sciences, from philosophy, psychology, political and social economy, and their application to the elucidation of the causes, nature and treatment of such diseases, deformities and injuries as are liable to afflict our race. Therefore, the student of medicine in its general sense

* 'resented in a Symposium on Dental Education before the Section on Stomatology, at the Fifty-first Annual Meeting of the American Medical Association, held at Atlantic City, N. J., June 5.8. 1900 .

1. Chicago Medical Examiner, September, 1865, p. $\mathbf{5 7 6}$ 